\title{
Unusual intraorbital foreign body
}

\author{
Ramesh Srirangam, ${ }^{1}$ Suvarna K Gokhale, ${ }^{2}$ Adwait Uday Kulkarni, ${ }^{3}$ Kiran S Gadre ${ }^{4}$ \\ ${ }^{1}$ Department of Maxillofacial Surgery, Bharati Vidyapeeth Dental University, Pune, Maharashtra, India \\ ${ }^{2}$ Department of Opthalmology, Shashwat Hospital, Pune, Maharashtra, India \\ ${ }^{3}$ Department of Oral and Maxillofacial Surgery, Sinhgad Dental College and Hospital, Pune, Maharashtra, India \\ ${ }^{4}$ Department of Oral and Maxillofacial Surgery, Bharati Vidyapeeth Dental College and Hospital, Pune, Maharashtra, India \\ Correspondence to Dr Adwait Uday Kulkarni, dradwaitkulkarni@gmail.com
}

\section{Summary}

A case of a 41-year-old patient presenting late post-trauma with out any major signs or symptoms is presented herewith. On radiological investigation, a peculiar foreign body was identified in the orbital floor. To our surprise the point of entry of the foreign body was not proportionate with the size of it. Moreover, the trajectory and final location of foreign body did not concur with the symptom less presentation of patient. After what was thought to be adequate investigation, the patient was taken under general anaesthesia to reveal an additional foreign body that put most of the preoperative queries to rest. This case in retrospect emphasises the need for ruling out foreign body in the case of any penetrating injury of orbit with the help of not just radiographs and CT scans but also ultrasonography and MRI.

\section{BACKGROUND}

Cases of foreign body orbit are noted dime a dozen in the literature as well as clinical practice. However, even such common condition may manifest in perplexing and surprising way to the surgeon even after imaging with CT scans. We encountered two such surprises: (1) The dynamics of injury where a peculiar foreign body like a spring, ended up in this particular location without causing any morbidity or immediate symptom and (2) intraoperative, retrieval a plastic pen cap, which proves that only a thin slice CT scan is inadequate for complete identification of nature of an intraorbital foreign body and the need for ultrasonography (USG) and MRI cannot be over-rated.

To emphasise the need for careful selection of MRI and/ or USG along with CT scan when investigating for an intraorbital foreign body, especially of the ferrous nature.

\section{CASE PRESENTATION}

A 41-year-old male patient presented with a complaint of swelling on the left upper eyelid since 5 months with no ocular complaints. He had a history of a minor roadside accident 10 months back (fall from a two wheelerscooter and had suffered transient unconsciousness). At that time, he had a left black eye with very small lacerated wound on the upper eye lid near medial canthus (on lid crease) that did not require any suturing at that time and hence treated on outpatient basis at some other hospital for the same. He recovered within 15 days with no diminished vision, diplopia, etc. Five months post-trauma, he noticed a very small non-tender swelling on left upper lid at the site of injury, which increased in size over next 3-4 months.

At the time when he presented to us, a small 3-4 mm hard, non-tender swelling was present on the left upper eyelid at the medial end of the upper lid crease (figure 1). Slight lid lag on closure of the upper lid on the medial

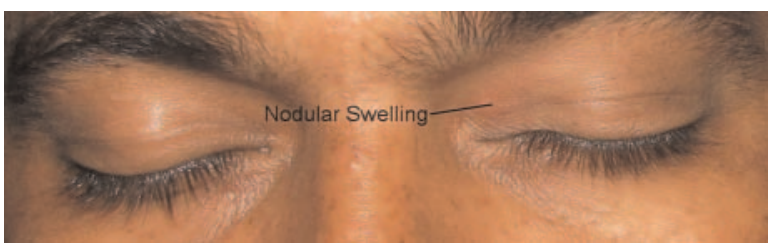

Figure 1 Photograph showing 3-4 mm nodular swelling at the left upper lid.

side was noticed. The swelling was fixed to the deeper conjunctiva near caruncle. Best-corrected visual acuity of both eyes was 20/20 with normal extraocular movements. Foreign body in the form of gravel or sand was suspected.

\section{INVESTIGATIONS}

The X-rays, Waters view and Lateral view of the orbit (figures 2 and 3 ) revealed a coiled metallic object mimicking a spring, $30 \mathrm{~mm}$ in length, $5-6 \mathrm{~mm}$ in diameter in left orbital cavity and left maxillary antrum. CT scan revealed a metallic foreign body placed in left extraconal space and extending from infero-medial angle of the orbit and piercing the roof of maxillary sinus and reaching up to postero-lateral wall of maxillary sinus (figure 4)..

\section{TREATMENT}

The patient was investigated for fitness and then under general anaesthesia via trans-oral Caldwel-Luc approach the maxillary antrum was opened. Under fibre optic illumination, a green-coloured pen cap was noticed. It was removed without any hindrance. The coiled spring within it was revealed. The spring was found to be partly embedded in the orbital cavity and partly exposed into the antrum through the roof. The spring was uncoiled in anticlockwise direction with an artery forceps to aid 


\section{BMJ Case Reports}

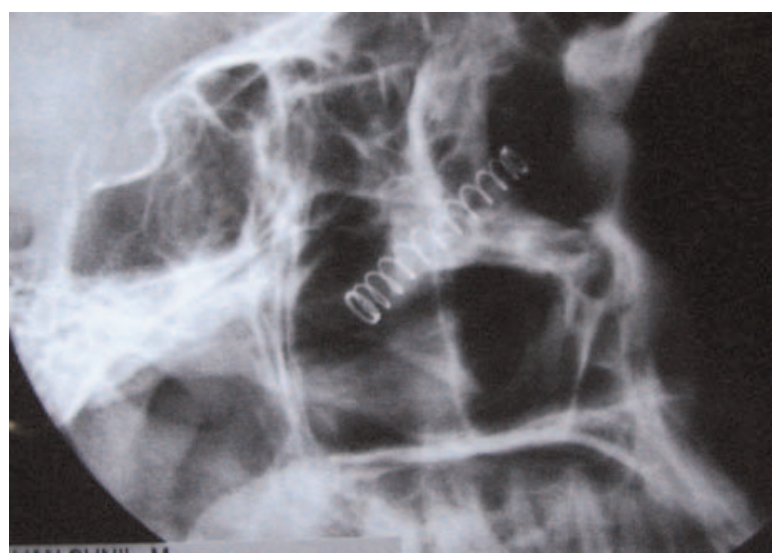

Figure 2 Lateral orbital view of the left orbit showing coiled metallic object in the orbital and antral cavity penetrating the orbital floor.

removal. Thus, only an intraoral approach was used and any extraoral approach was avoided along with the possible associated scar. The intraoral incision was closed, patient reversed and shifted out of the operating room uneventfully.

\section{OUTCOME AND FOLLOW-UP}

The patient made an uneventful recovery in 8 days with normal ocular motility and vision.

\section{DISCUSSION}

Transorbital penetrating injuries are well described in the literature. $^{1} 2$ Such penetrating injuries can penetrate superiorly into the cranial cavity ${ }^{3}$ or inferiorly into the antrum owing to thin nature of the bony orbital skeleton. Penetrating objects are usually metallic ${ }^{4-7}$ or wooden. ${ }^{2}$ Occasional pencil injuries have been reported. Late presentations of such cases are due to formation of

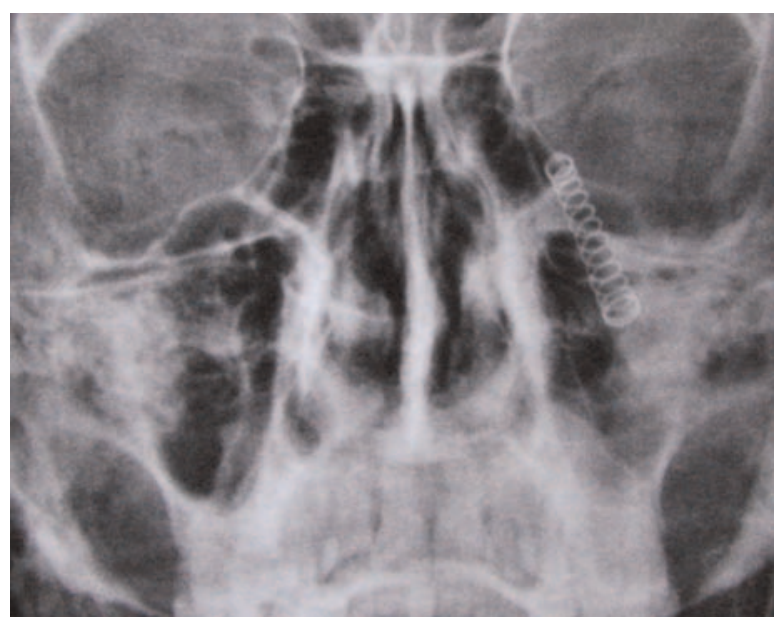

Figure 3 Water's view showing a coiled metallic object mimicking spring in relation to left inferio-medial aspect of orbit running obliquely lateral in antrum.

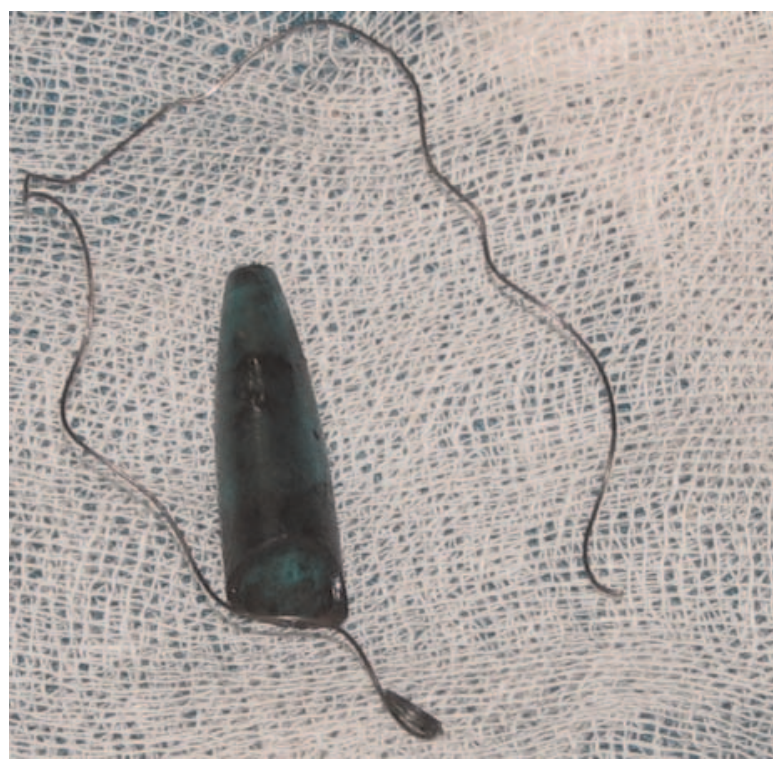

Figure 4 Photograph of pen cap and uncoiled spring after surgical removal.

swelling or abscess or deteriorating visual acuity due to foreign body reaction. A high suspicion index of foreign bodies in such penetrating injuries should be in mind of the attending surgeon and should be ruled out with careful clinical examination and imaging; as late presentations of such injuries are often associated with considerable morbidity. ${ }^{1} 38$ Nature of the foreign body has specific implications with regard to imaging modality. Whereas metallic objects are easily identified on x-ray and CT scan, non-metallic foreign bodies may be revealed on ultrasonography or MRI. In our case, x-ray and CT scan should have prompted to suspect pen cap (conical object) to cause a penetrating injury, as it is rather difficult to explain the dynamics of trauma that led to only a coiled spring to penetrate the structures in the manner that was detected in our case. Although $\mathrm{MRI}^{3}$ or ultrasonography may have been useful to reveal the same in our case, the presence of coiled spring on radiography raised a high suspicion index of its probable ferrous nature and hence MRI as a diagnostic tool was ruled out. ${ }^{9}$ In the event that the removal of the entire metallic foreign body cannot be verified or if there is insufficient information to confirm that there is no metallic foreign body present, screening radiography should be used prior to $\mathrm{MRI}^{9}$ which could be catastrophic in the presence of ferrous object.

Early identification and removal of foreign bodies is associated with better prognosis ${ }^{6}$ and minimal complications as all patients are not as lucky as our patient to escape the late complication of such injuries. Our search has failed to locate similar report in English literature where the point of penetration has been upper eyelid and the object has travelled across the medial aspect of the orbit and entered the antrum without loss of vision and ocular motility. In our opinion the pen cap protected the vital structures due to its inherent shape escorting the spring into the sinus. 


\section{BMJ Case Reports}

\section{Learning points}

- In the case of any injury, presence of penetrating foreign body should be suspected.

- Investigations for foreign bodies in the maxillofacial region should not cease with $\mathrm{x}$-rays and CT scan but should also include MRI, ultrasonography, etc.

- Although MRI would be the best available option to detect non-metallic objects, it should be used with utmost caution if the history and circumstances of trauma raise a high suspicion of metallic objects and more so of the ferrous type. Moreover, MRI investigation should always be preceded by simple radiography and CT scan to rule out such objects.

- Multidisciplinary approach is always beneficial when dealing with complex trauma of the head neck region.

\section{REFERENCES}

1. Polini F, Robiony M, Toro $C$, et al. Penetrating injury of the facial skeleton through the orbit, by a massive metallic shotgun block: a case report. $\mathrm{Br} J$ Oral Maxillofac Surg 2007:45:586-7.

2. Bater MC, Scott R, Flood TR. Use of an inferior orbitotomy for safe removal of a wooden foreign body penetrating the orbit. Br J Oral Maxillofac Surg 2007:45:664-6.

3. Davis GA, Holmes AD, Geoffrey L. Delayed presentation of transorbital intracranial pen. J Clin Neurosci 2000;7:542-60.

4. Sadda Raid S. Fish gun injury of the maxillofacial region. J Oral Maxillofac Surg 1996;54:1132-5.

5. Erisen L, Basut 0 , Coskun $\mathrm{H}$, et al. An unusual penetrating facial injury due to a fishing-line sinker. J Oral Maxillofac Surg 2001;59:945-7.

6. Harris M, Mintz S, Kaltman S. Traumatic penetrating injuries to the maxillary sinus: a retrospective review of the world literature and case report. Oral Surg Oral Med Oral Pathol Oral Radiol Endod 2006;101:45.

7. Fan VTW, Korvi S. Sewing needle in the maxillary antrum. J Oral Maxillofac Surg 2002;60:334-6.

8. Arora V, Kim UR, Shetty S, et al. Atypical presentation of an unusual foreign body. Indian J Ophthalmol 2010;58:338-9.

9. Shellock FG, Kanal E, SMRI safety committee. Policies, guidelines, and recommendations for MR imaging safety and patient management. J Magn Reson Imaging 1991;1:97-101.

\section{Competing interests None.}

Patient consent Obtained.

This pdf has been created automatically from the final edited text and images.

Copyright 2012 BMJ Publishing Group. All rights reserved. For permission to reuse any of this content visit

http://group.bmj.com/group/rights-licensing/permissions.

BMJ Case Report Fellows may re-use this article for personal use and teaching without any further permission.

Please cite this article as follows (you will need to access the article online to obtain the date of publication).

Srirangam R, Gokhale SK, Kulkarni AU, Gadre KS. Unusual intraorbital foreign body. BMJ Case Reports 2012;10.1136/bcr-12-2011-5377, Published XXX

Become a Fellow of BMJ Case Reports today and you can:

- Submit as many cases as you like

- Enjoy fast sympathetic peer review and rapid publication of accepted articles

- Access all the published articles

- Re-use any of the published material for personal use and teaching without further permission

For information on Institutional Fellowships contact consortiasales@bmjgroup.com

Visit casereports.bmj.com for more articles like this and to become a Fellow 